\title{
EVOLUTION OF THE MICROSTRUCTURE AND PERFORMANCE OF Pd/Ag - BASED THICK CONDUCTORS
}

\author{
MARIA PRUDENZIATI, BRUNO MORTEN \\ Dipartimento di Fisica dell'Università di Modena, Italy \\ and \\ MARIA FRANCA BRIGATTI \\ Istituto di Mineralogia e Petrologia dell'Universita di Modena, Italy \\ (Received April 20, 1984; in final form September 18, 1984)
}

\begin{abstract}
$\mathrm{Pd} / \mathrm{Ag}$-based inks are probably the most commonly used conductors in thick-film hybrid technology. The evolution of the microstructure of these films was studied on samples fired with isochronal cycles at a peak temperature in the range from $300^{\circ} \mathrm{C}$ up to $850^{\circ} \mathrm{C}$. The samples were investigated by means of X-ray diffraction, SEM and EDAX analysis techniques; the results of these analyses as well as those of thermogravimetry (TG, DTG) and differential thermal analysis (DTA), enable one to obtain a clear picture of the complex evolution of the microstructure of these conductors, which correlates quite strictly with the performance of the films in terms of resistivity and adhesion.

The relevance and limitations of each analytical technique for the examination of thick-film conductors are emphasized.
\end{abstract}

\section{INTRODUCTION}

$\mathrm{Pd} / \mathrm{Ag}$ based conductors are probably the most commonly used inks in the technology of thick-film hybrid circuits. ${ }^{1}$ These materials are preferred to Ag-based conductors when the solderability and reduced electromigration and diffusion in resistors are a premium, with a small sacrifice in terms of conductivity and without the disadvantage of high prices of Au-, Pt-based materials as well as their alloys.

Some basic features concerning the formation of the microstructure of these films have been approached by several authors. ${ }^{2-7} \mathrm{Coles}^{2-3}$ studied the sintering behavior of Ag-Pd compacted powders without or in presence of a glass-frit; Wirth and Miller ${ }^{5}$ described the main requirements for the ink formulation and some correlation between the ink components and the final film performance. Moreover adhesion studies have received extensive consideration. ${ }^{6-7}$

In this paper we will present and discuss the results of a study, performed on a specific Pd-Ag-based material, with the aim of establishing a methodology for the investigation of the evolution of the microstructure of an actual material and its correlations between the different stages of the evolution and the performance of the film in terms of resistivity and adhesion.

The study was successful in both the aims of getting interesting information on the material examined and giving definite evaluation of the applicability and limitations of several analytical techniques in the study of thick-film conductors.

\section{SAMPLES AND METHODS}

The data reported in the paper concern the ink C4308 from Cermalloy Heraeus. This is a material well representative of the class of PdAg-based conductors with a relatively large amount of $\mathrm{Pd}$, as observed in an exploratory investigation. 


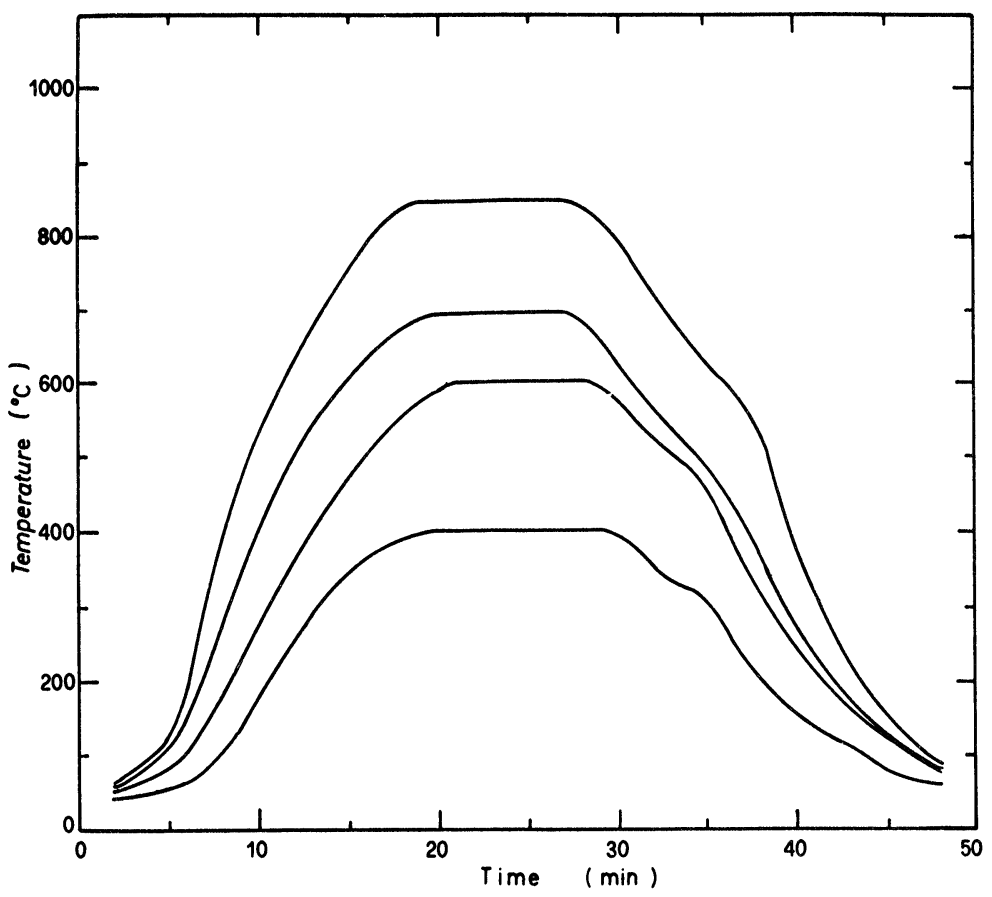

FIGURE 1 Some isochronal firing cycles for the preparation of samples of the present study.

For the characterization of the ink, thermogravimetric (TG, DTG) and differential thermal analysis (DTA) were used as well as X-ray diffraction (XRD), scanning electron microscopy (SEM) associated with an energy-dispersive electroninduced X-ray fluorescence (EDAX).

The EDAX equipment was fitted with a minicomputer which allows the semiquantitative evaluation of detectable elements $(Z \geqslant 9)$ with a sensitivity of $0.1 \%$. The accuracy of our analyses is limited in the present study by the morphology of the samples examined, as will be shown later. The EDAX analyzer enables determination of the elemental distribution maps for a chosen element in the sample.

XRD, SEM, and EDAX analyses were also used for study of the evolution of the microstructure of the films.

Measurements of the electrical conductivity were performed on meander patterns consisting of 112 squares as well as with the four-point probe method on large deposits $\left(15 \times 15 \mathrm{~mm}^{2}\right)$.

The adhesion of the films was characterized in terms of the pool strength on small pads $\left(1.5 \times 2 \mathrm{~mm}^{2}\right)$ with the method described in Reference 6 .

Samples were screen printed on $96 \%$ alumina substrates and dried at $150^{\circ} \mathrm{C}$ or $200^{\circ} \mathrm{C}$ for $20 \mathrm{~min}$. Two sets of samples with a dry-thickness of 33 and $17 \mu \mathrm{m}$ respectively were prepared.

The samples were then fired, following isochronal firing cycles (Figure 1) having a different peak temperature $T_{f}$ and equal dwell times. $T_{f}$ ranged from $300^{\circ} \mathrm{C}$ up to $850^{\circ} \mathrm{C}$, with a constant increment of $50^{\circ} \mathrm{C}$.

For DTA experiments the ink was diluted in acetone and the solution was centrifuged in order to collect a dry powder from which most of the organic vehicle is removed. 
For SEM and EDAX experiments cross sections of the samples were prepared; the substrate, scribed on the back surface by a pulsed laser beam, was snapped at a very low temperature, i.e. after quick extraction from a liquid nitrogen bath.

Furthermore an in-depth analysis of the elemental composition was performed on samples fired at $\mathrm{T}_{\mathrm{f}}=850^{\circ} \mathrm{C}$ and then reduced to a desired thickness by means of a lapping procedure with diamond pastes.

The film thickness was measured with a Rank Precision Talysurf 10 system.

\section{EXPERIMENTAL RESULTS}

The ink

Figure 2 shows the results of a TG and DTG analysis of the ink in air flow.

The total weight loss at lower temperatures corresponds to a content of organic vehicle larger than $35 \%$; this latter consists of a highly volatile component, which evaporates in the range from about $100^{\circ} \mathrm{C}$ to $200^{\circ} \mathrm{C}$, as well as two components which are completely removed at about $350^{\circ} \mathrm{C}$.

A further interesting feature of the TG curve is the weight gain observed in the range from $400^{\circ} \mathrm{C}$ to $500^{\circ} \mathrm{C}$ and the subsequent regain of the original weight value at about $600^{\circ} \mathrm{C}$. This behavior is due to the oxidation process of the Pd particles and the subsequent reduction of $\mathrm{PdO}$, as can be argued from the nature of the sample and confirmed by the results of XRD analysis, reported below. TG traces were made at different heating rates of the sample in the range from 20 to $60^{\circ} \mathrm{C} / \mathrm{min}$ without observing significant changes in the results.

Figure 3 shows typical results of DTA analyses on the powder extracted from the ink. Three exothermic peaks are apparent with peak temperature at about $290^{\circ} \mathrm{C}, 440^{\circ} \mathrm{C}$ and $550^{\circ} \mathrm{C}$ together with an endothermic peak at about $750^{\circ} \mathrm{C}$. A

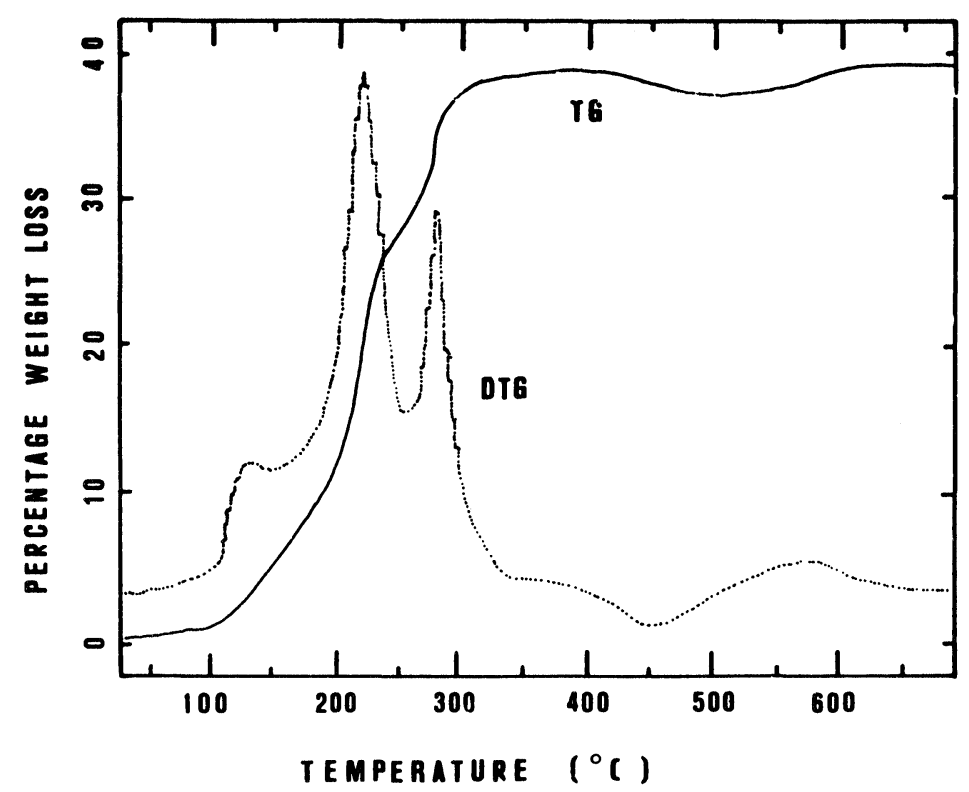

FIGURE 2 TG curve (continuous line) and its derivative (broken line) of the ink. Note the weight loss due to evaporation and burnout of the organic vehicle and the gain in weight due to an oxidation process. 


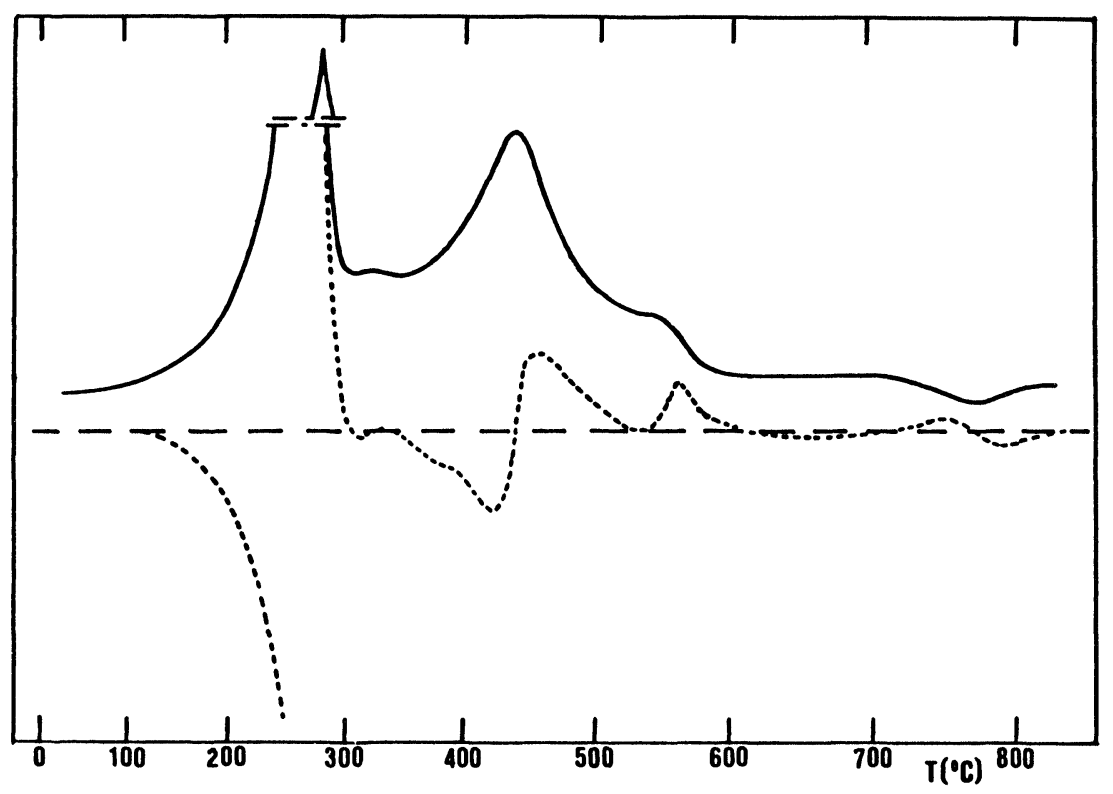

FIGURE 3 DTA curve for the ink after removal of most of the organic vehicle.

comparison of TG, DTG and DTA results suggests that the peak at $290^{\circ} \mathrm{C}$ could be associated with the burnout of a component of the organic vehicle insoluble in acetone. Moreover it seems reasonable to connect the peak at $440^{\circ} \mathrm{C}$ with the oxidation-reduction process of the Pd grains. The XRD data presented below also suggest that the $550^{\circ} \mathrm{C}$ peak could be associated with some phase-transition(s) occurring within the system, including the PdAg alloy formation and reaction of bismuth- oxide with the glass-frit. However the complexity and time-superposition of several phase changes occurring in the system analyzed make the DTA data poorly informative.

Nonetheless, it is interesting to argue about the origin of the endothermic peak; this latter could be due to the softening of the glass, starting from about $700^{\circ} \mathrm{C}$, without a real phase transformation. In fact the area and height of the endothermic peak are both small and no phase change is detected with XRD experiments in the range from $700^{\circ} \mathrm{C}$ to $850^{\circ} \mathrm{C}$.

Figure 4 shows the SEM picture of some particles contained in the ink. In order to get these isolated grains a small amount of the paste was dispersed in a large volume of acetone and a drop of the solution was placed on a stub for SEMEDAX analysis. In this way, the presence of individual grains of $\mathrm{Ag}$ (mean size $0.2-3 \mu \mathrm{m}), \mathrm{Pd}($ most with a size of $0.02-0.2 \mu \mathrm{m}$ ) and of glassy particles (namely, grains rich in $\mathrm{Pb}$ and $\mathrm{Si}$ ) was detected. In the same sample, flakes rich in $\mathrm{Bi}$ can be observed.

Besides the elements mentioned, $\mathrm{Al}$ and $\mathrm{Zn}$ were also detected with EDAX analysis of the dried paste. The evaluation of the relative concentration of these elements in the paste is necessarily very approximate, because of the following experimental factors:

a) the EDAX technique is unable to detect $\mathrm{B}$ (which is probably present as a constituent of the glass frit) as well as other light $(Z<10)$ elements; 


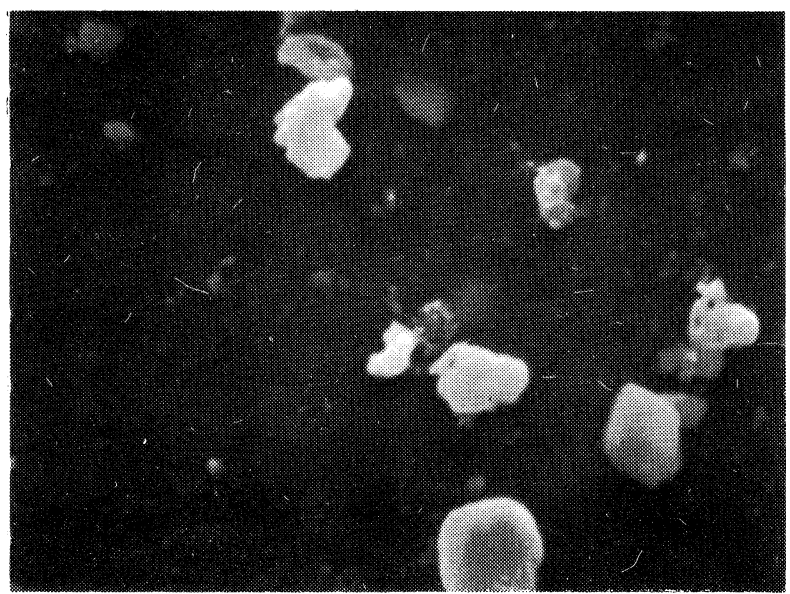

FIGURE 4 Particles present in unfired ink; the smallest grains are identified as $\mathrm{Pd}$, the medium sized grains are due to $\mathrm{Ag}$, the largest particles are rich in $\mathrm{Pb}$ and $\mathrm{Si}$ and can be associated with the glass frit.

b) the stoichiometry ratio of each element with 0 can only be argued from experience or data from independent experiments;

c) the actual poor density of the sample. In fact EDAX semiquantitative analyses are based on computer programs which calculate the relative concentration of the detected elements by means of an iterative procedure which processes the rough experimental data and corrects them for effects of the sample's effective atomic number, autoabsorption and internal fluorescence. ${ }^{9}$ The iterative procedure converges to a reliable and accurate result only when the actual density of the sample approaches the "theoretical" density figured out by the computer program on the basis of the sample composition. In reality, however, a dried paste contains the organic vehicle not completely removed while the film contains voids, open pores, etc. The ink has a very low density compared with the "theoretical" value; on the other hand it is quite hard to change the computer program in order to enable it to account for this situation.

All these considerations account for the discrepancy between the EDAX results, shown in Table I, and those obtained with other analytical methods (see below). In particular the data of Table I give a ratio $\mathrm{Ag} / \mathrm{Pd}$ equal to $73 / 27$, while the actual ratio is $81 / 19$. This latter result is, in fact, obtained from the X-ray diffraction patterns, when the areas of equivalent peaks of the spectra due to $\mathrm{Pd}$ and $\mathrm{Ag}$ grains are considered.

In fact, since $\mathrm{Pd}$ and $\mathrm{Ag}$ are completely isomorphous and give reflections at nearly equal Bragg angles, a simple relation holds for the ratio of the areas $\mathrm{A}_{\mathrm{Ag}} / \mathrm{A}_{\mathrm{Pd}}$ of equivalent peaks:

$\mathrm{A}_{\mathrm{Ag}} / \mathrm{A}_{\mathrm{Pd}}=\left(\mathrm{F}_{\mathrm{Ag}} / \mathrm{F}_{\mathrm{Pd}}\right)\left(\mathrm{C}_{\mathrm{Ag}} / \mathrm{C}_{\mathrm{Pd}}\right)$

TABLE I

Relative concentration of detectable components in the paste (\% in weight) from a semiquantitative EDAX analysis.

\begin{tabular}{lllllll}
\hline $\mathrm{Ag}$ & $\mathrm{Pd}$ & $\mathrm{Bi}_{2} \mathrm{O}_{3}$ & $\mathrm{Al}_{2} \mathrm{O}_{3}$ & $\mathrm{SiO}_{2}$ & $\mathrm{PbO}$ & $\mathrm{ZnO}$ \\
55.86 & 20.95 & 13.90 & 1.05 & 1.93 & 2.73 & 3.58 \\
\hline
\end{tabular}




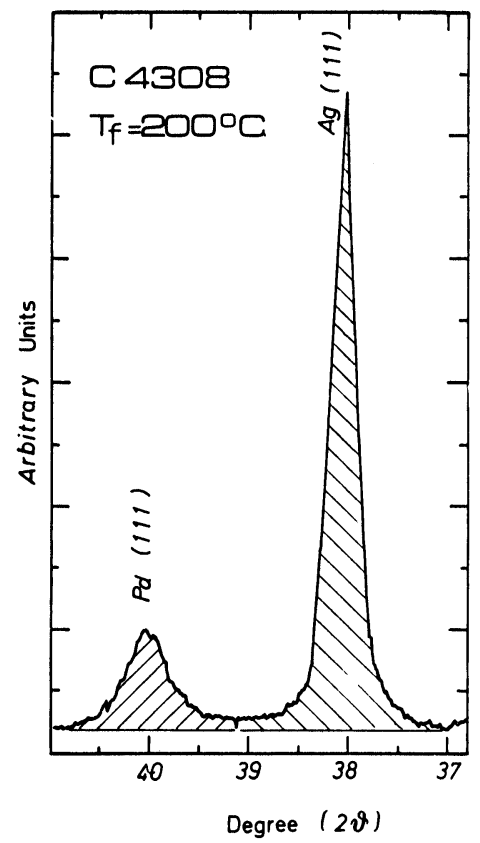

FIGURE 5 Diffraction pattern of $\mathrm{d}_{(111)}$ peaks of $\mathrm{Ag}$ and $\mathrm{Pd}$ grains in the paste dried at $200^{\circ} \mathrm{C}$.

where $\mathrm{F}$ represents the atomic form factor and $\mathrm{C}$ the atomic concentration. Moreover in a first approximation $\mathrm{F}_{\mathrm{Ag}} / \mathrm{F}_{\mathrm{Pd}}=\mathrm{Z}_{\mathrm{Ag}} / \mathrm{Z}_{\mathrm{Pd}}$ for $\mathrm{d}_{(111)}$ reflections. ${ }^{10}$

On the basis of these considerations, the ratio of the areas of peaks $d_{(111)}$ (Figure 5) gives for the concentration $\mathrm{Ag} / \mathrm{Pd}=81 / 19$ at. Moreover from the peak broadening we have for the mean sizes of metal grains in the dried paste: $1250 \AA$ for $\mathrm{Ag}$ grains and about $250 \AA$ for $\mathrm{Pd}$ grains, in reasonably good agreement with SEM observations.

Besides the peaks of $\mathrm{Ag}$ and Pd phases, the diffraction patterns of the fried ink show reflections due to a $\mathrm{Bi}_{2} \mathrm{O}_{3} \alpha$-pseudorhombic phase. These microcrystals are occasionally seen in SEM observations are shown by the picture of Figure 6 and the elemental distribution map of $\mathrm{Bi}$ for the same area.

\section{Evolution of the microstructure of the film}

Figure 7 shows the change of thickness of the film due to the firing process at different peak temperatures $T_{f}$. An appreciable shrinkage in the film occurs starting from $650-700^{\circ} \mathrm{C}$. A film fired at $850^{\circ} \mathrm{C}$ has this thickness equal to one half of that of a dried film.

Shrinkage and sintering are only a few of the numerous and interesting phenomena occurring during the firing cycle of the conductive layer.

$\mathrm{X}$-ray diffraction patterns of the samples contain several pieces of information on these phenomena. Figure 8 shows the more informative parts of the patterns of samples dried at $200^{\circ} \mathrm{C}$ and fired at 400,600 and $850^{\circ} \mathrm{C}$ respectively. Up to $350^{\circ} \mathrm{C}$ the samples contain only $\mathrm{Pd}, \mathrm{Ag}$ and $\mathrm{Bi}_{2} \mathrm{O}_{3}$ crystalline phases, at $350^{\circ} \mathrm{C}$ a $\mathrm{PdAg}$ alloy starts to appear; at $400^{\circ} \mathrm{C}$ the formation of the $\mathrm{PdO}$ phase becomes evident. By increasing the firing temperature $T_{f}$ the reflections due to $\mathrm{PdAg}$ alloy shift at different Bragg angles according to Vegard's law, ${ }^{10}$ until, at about $650^{\circ} \mathrm{C}$, a steady 
state situation is reached for the alloy. In the meanwhile the $\mathrm{PdO}$ phase vanishes and a new phase is detected, which can be identified as $12 \mathrm{Bi}_{2} \mathrm{O}_{3} \cdot 2 \mathrm{SiO}_{2}$ (cubic phase). In samples fired at $850^{\circ} \mathrm{C}$ no other phase other than the $\mathrm{AgPd}$ alloy is observed in the diffraction patterns.

It is worth noting that these results are observed in both sets of samples with dry-thickness of 17 and $33 \mu \mathrm{m}$, and then on samples about $8 \mu \mathrm{m}$-thick when fired at $850^{\circ} \mathrm{C}$; on the other hand the diffracted X-rays come from a comparable depth in the samples. This means that the $12 \mathrm{Bi}_{2} \mathrm{O}_{3} \cdot \mathrm{SiO}_{2}$ phase actually dissolves away rather than segregating at the film/substrate interface.

Figure 9 summarizes the results of X-ray diffraction experiments in terms of the relative peak heights as a function of $\mathrm{T}_{\mathrm{f}}$. The XRD data on $\mathrm{PdO}$ agree fairly well with those of TG analysis. Moreover the reduction of $\mathrm{Bi}_{2} \mathrm{O}_{3}$ and the apparance of a phase involving the chemical reaction of $\mathrm{Bi}$ and $\mathrm{Si}$ are clearly mutually correlated, according to the data of Figure 9. This could be explained by the consideration that $\mathrm{Bi}_{2} \mathrm{O}_{3}$ is a quite stable compound with a melting point at about $850^{\circ} \mathrm{C}$; consequently its reduction to $\mathrm{Bi}$ could be required for the formation of the new phase.

Information on the PdAg alloy formation is obtained by the analysis of the XRD data (Table II). $\mathrm{Pd}$ and $\mathrm{Ag}$ grains start to react at about $350^{\circ} \mathrm{C}$ where very small grains of the alloy are formed, rich in Pd. However at this stage of the firing process individual particles of $\mathrm{Ag}$ and $\mathrm{Pd}$ are still present. By increasing the firing temperature a complete alloy formation is obtained and the final alloy composition corresponds to a ratio $\mathrm{Ag} / \mathrm{Pd}$ equal to $80 / 20$. So the measurement of the alloy composition according to Vergard's law on the high-temperature fired samples compare well with that given by the ratio of the areas of peaks in dried samples.

The alloy formation also involves an increase of the grain size; in sample fired at $\mathrm{T}_{\mathrm{f}} \leqslant 350^{\circ} \mathrm{C}$ this size is still lower than $3000 \AA$ which is an upper boundary for size measurements through diffractometric techniques. ${ }^{10}$

For the study of necking and sintering, scanning electron microscopy is very suitable. Figure 10 shows some interesting stages of these phenomena.

The powderlike structure of samples fired at $500^{\circ} \mathrm{C}$ changes into the granular structure of samples fired at $650^{\circ} \mathrm{C}$ where some necks appear.

The density of the films at this stage is still very poor, as in a open-pore sintering stage. ${ }^{11-13}$ Only on samples fired at temperatures above $700^{\circ} \mathrm{C}$ are largely connected surfaces formed with a quasi-continuous network through characterized by some large but separate porosities.

TABLE II

Lattice spacing $(a)$, mean particle size $(\phi)$ and atomic percentage of Pd reacted in PdAg alloy, as a function of the peak firing temperature $T_{f}\left({ }^{\circ} \mathrm{C}\right)$.

\begin{tabular}{llllll}
\hline $\left.\mathrm{T}_{f}{ }^{\circ} \mathrm{C}\right)$ & $a(\AA)$ & $\phi_{\mathrm{Ag}}(\AA)$ & $\phi_{\mathrm{Pd}}(\AA)$ & $\phi_{\text {alloy }}(\AA)$ & $\% \mathrm{Pd}$ \\
\hline 150 & $\simeq 1250$ & $\simeq 250$ & & \\
350 & 4.0097 & & & & \\
500 & 4.0701 & & & $>2000$ & 85 \\
550 & 4.0576 & & $>2000$ & 12 \\
600 & 4.0475 & & $>2000$ & 19 \\
650 & 4.0470 & & & $>2000$ & 20 \\
700 & 4.0449 & & $>2000$ & 20 \\
750 & 4.0449 & & $>2000$ & 20 \\
850 & 4.0449 & & & & \\
\hline
\end{tabular}

The mean size of particles was determined from diffraction peak line broadening. Alloy composition was obtained from $a$ values according to Vegard's law and the correction factors by Rao and Rao. ${ }^{14}$ 

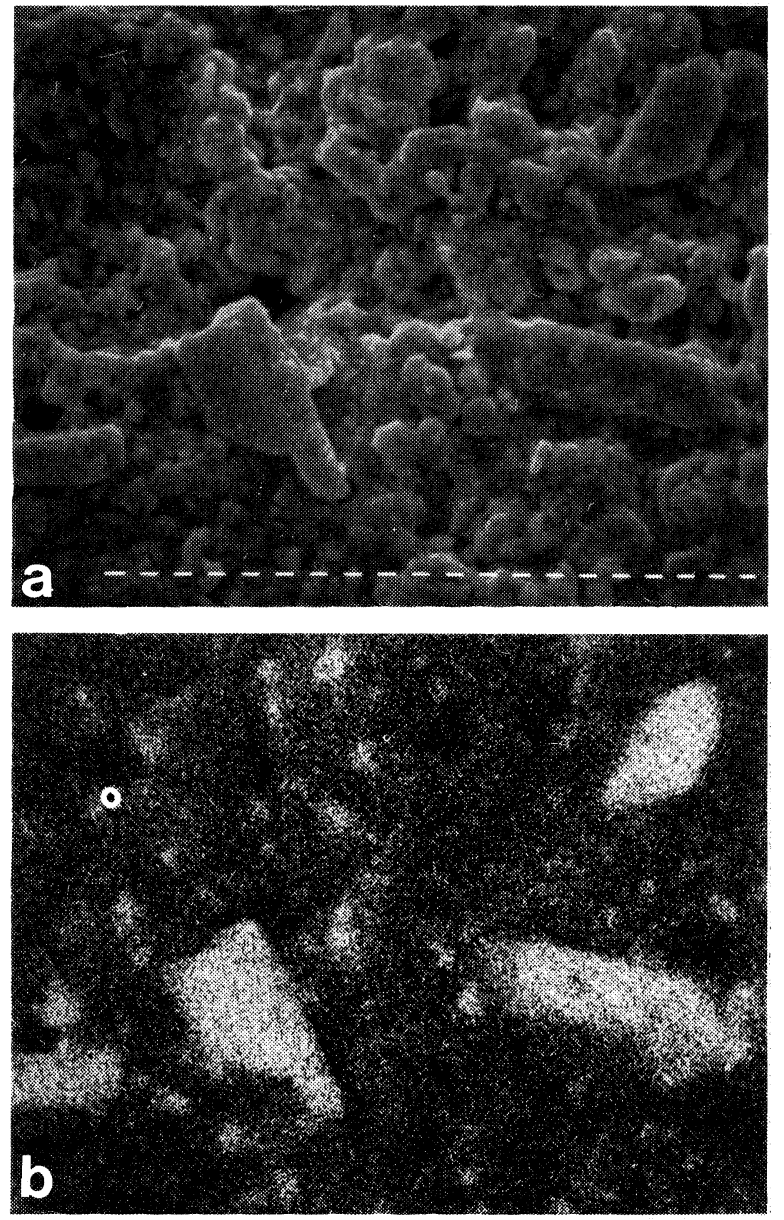

FIGURE 6 Microcrystals rich in $\mathrm{Bi}$ present in the paste dried at $200^{\circ} \mathrm{C}$. a) picture of the surface, b) distribution map of $\mathrm{Bi}$ for the same area.

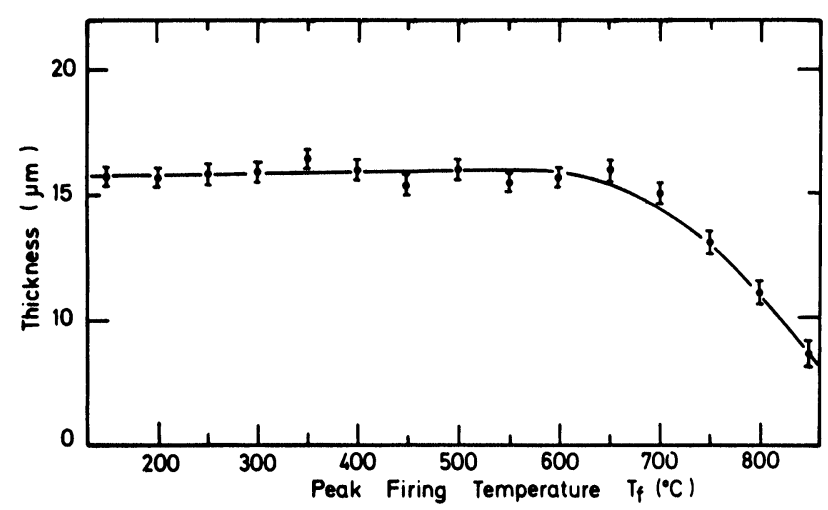

FIGURE 7 Thickness of the samples fired at the peak temperature $T_{f}$. 


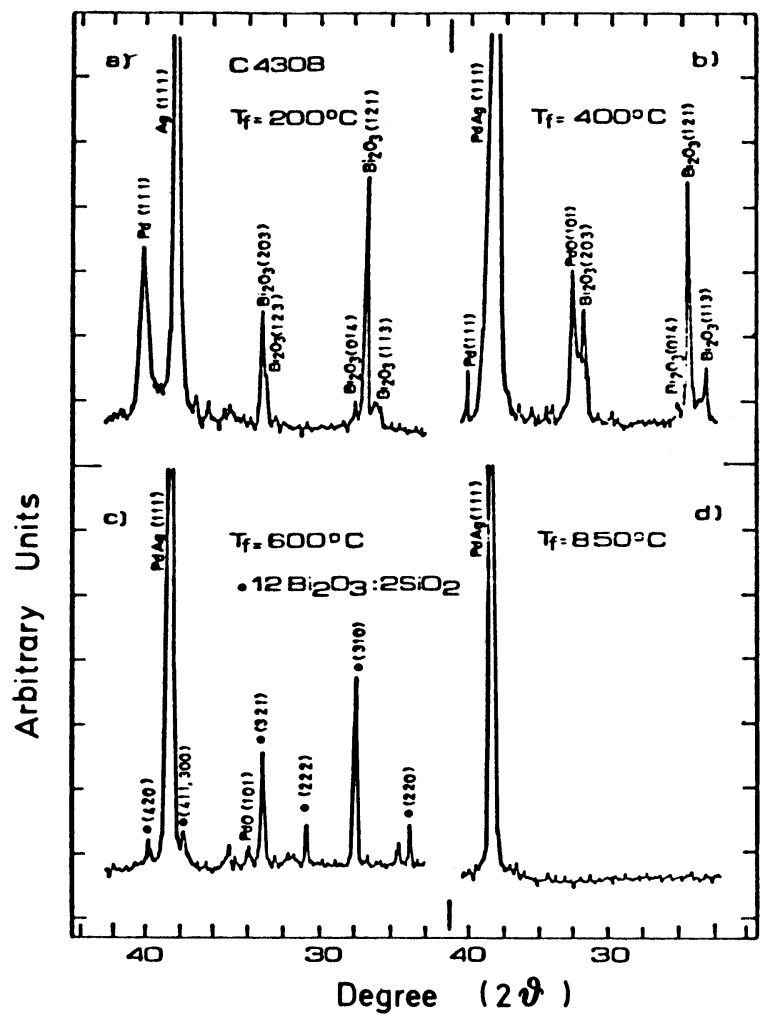

FIGURE 8 The most informative part of X-ray diffraction patterns of samples dried (a) and fired at $\mathrm{T}_{\mathrm{f}}=400^{\circ} \mathrm{C}(\mathrm{b}), 600^{\circ} \mathrm{C}(\mathrm{c})$ and $850^{\circ} \mathrm{C}(\mathrm{d})$.

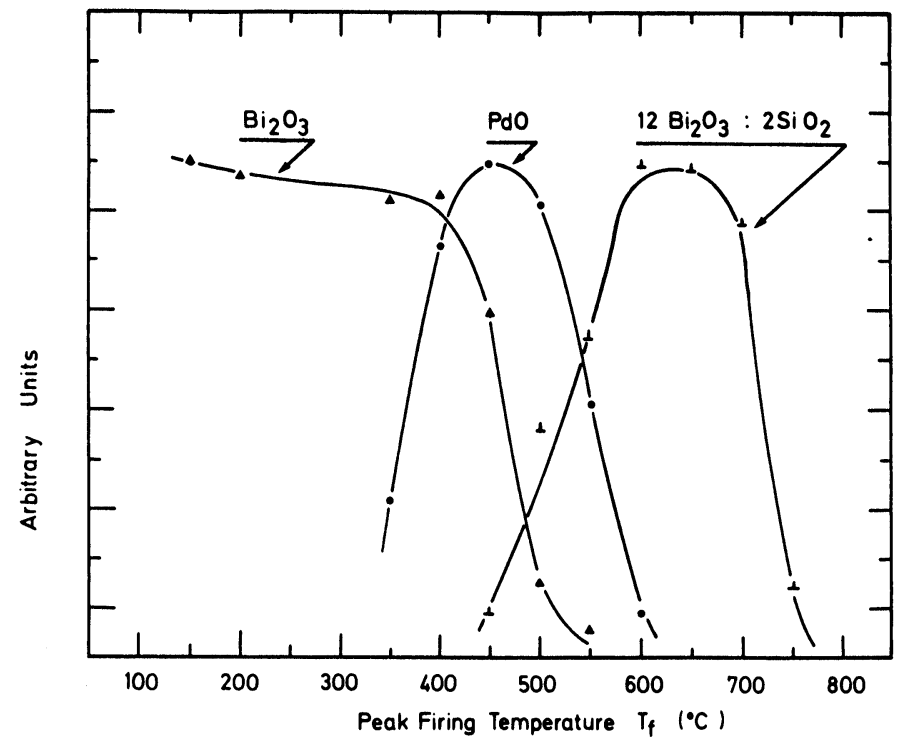

FIGURE 9 Relative intensity of some phases present in XRD patterns of samples fired at different peak temperatures $T_{f}$. 

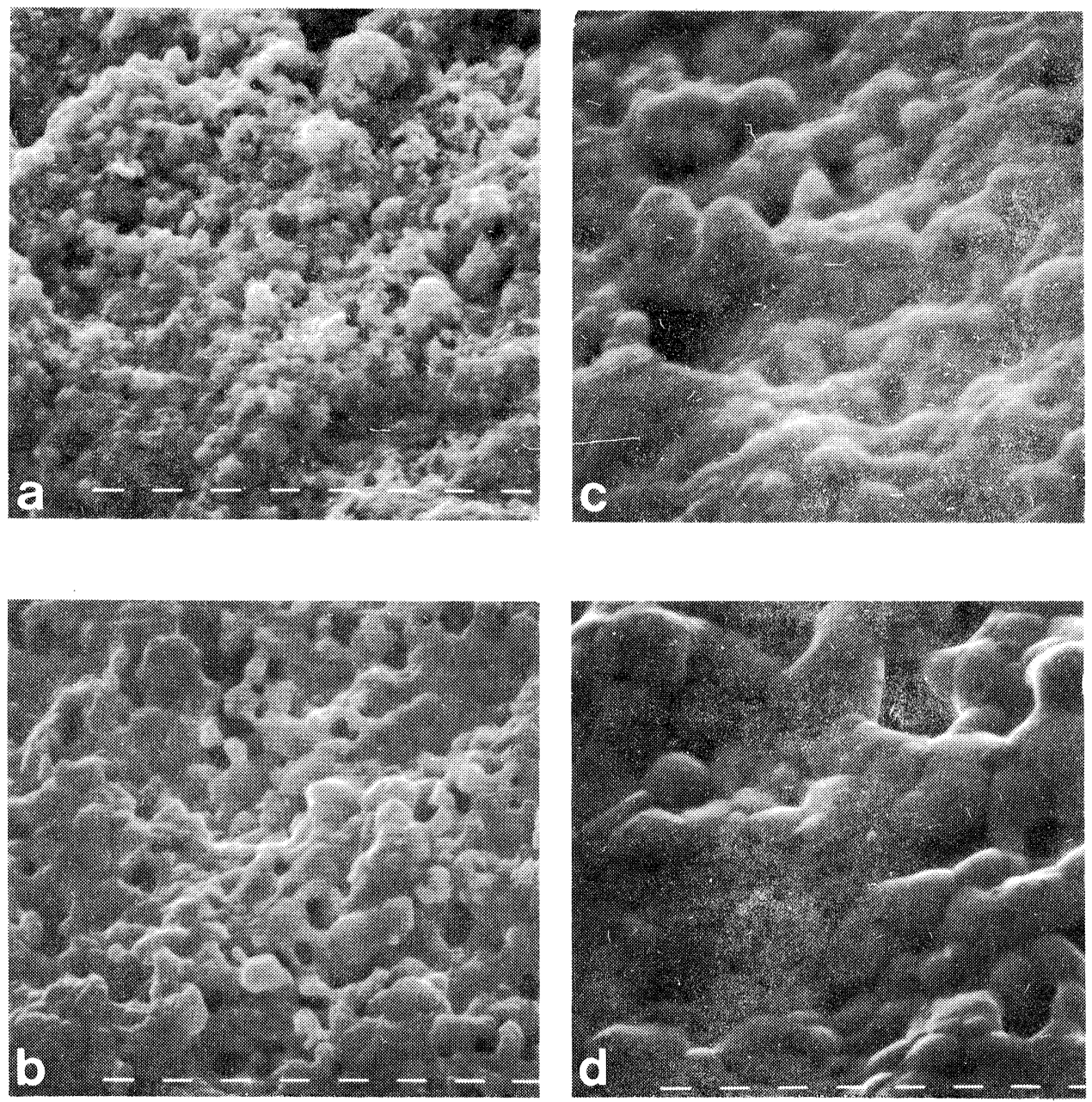

FIGURE 10 Some stages of the sintering process observed with SEM. The peak firing temperatures were $500^{\circ} \mathrm{C}(\mathrm{a}), 600^{\circ} \mathrm{C}(\mathrm{b}), 750^{\circ} \mathrm{C}(\mathrm{c})$ and $850^{\circ} \mathrm{C}(\mathrm{d})$.

A cross sectional view of samples fired at $650^{\circ} \mathrm{C}$ and $850^{\circ} \mathrm{C}$ respectively supports this picture, emphasizing also the shrinkage of the layer by increasing the temperature from $650^{\circ} \mathrm{C}$ to $850^{\circ} \mathrm{C}$ (Figure 11 ).

Occasionally SEM observations enable a corroboration of data already obtained by XRD experiments. An example is given in Figure 12, where the surface of a sample fired at $700^{\circ} \mathrm{C}$ is shown. Some crystals (linear size in the $\mu \mathrm{m}$ range) are evident; one of those in the central part of the picture is particularly notable for the clear cubic structure. The identification of these microcrystals with the $12 \mathrm{Bi}_{2} \mathrm{O}_{3} \cdot 2 \mathrm{SiO}_{2}$ phase is supported by EDAX distribution maps of $\mathrm{Bi}$ in the same area. 

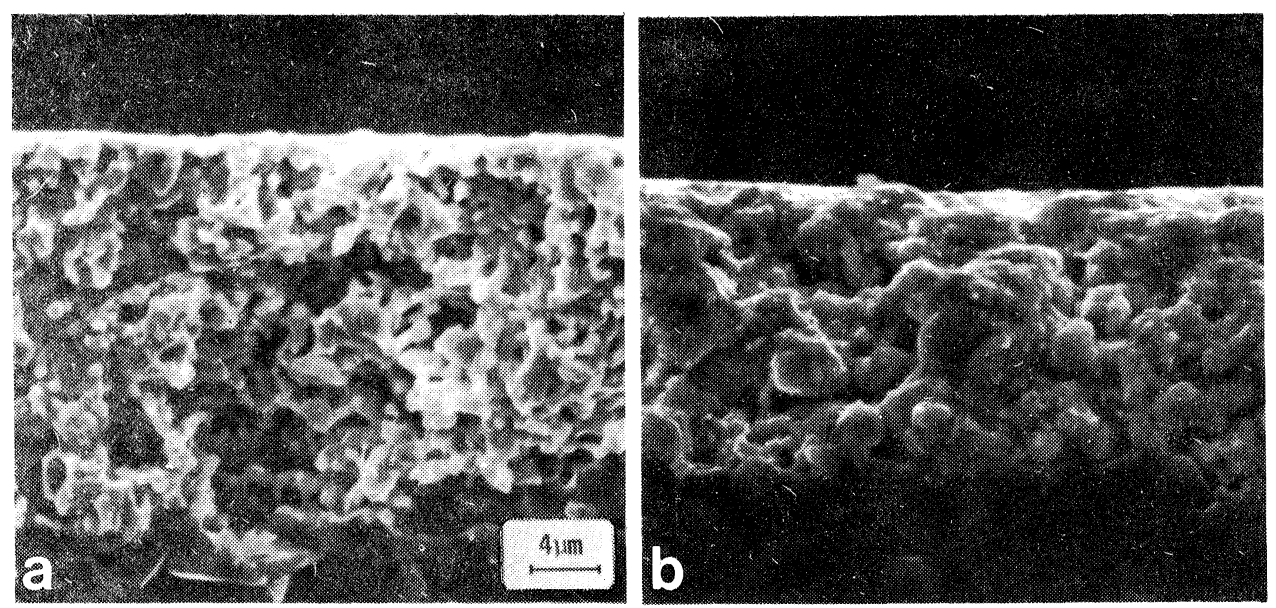

FIGURE 11 Cross sectional view of samples fired at $\mathrm{T}_{\mathrm{f}}=650^{\circ} \mathrm{C}(\mathrm{a})$ and $850^{\circ} \mathrm{C}(\mathrm{b})$. The difference in density and thickness should be noted.
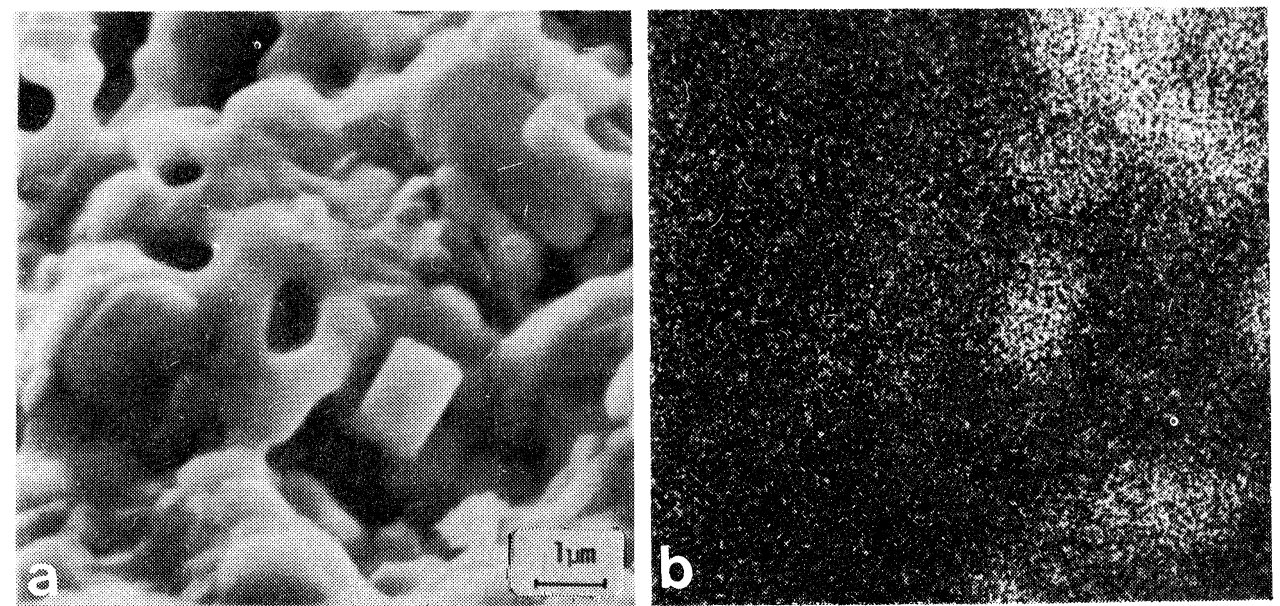

FIGURE 12 Some cubic crystals appearing on the surface of a film fired at $T_{f}=700^{\circ} \mathrm{C}(\mathrm{a})$ and the elemental distribution map of $\mathrm{Bi}$ for the same area.

EDAX enables the acquisition of data for the description of the evolution of the microstructure as regards the non-crystalline phase of the layer, namely the rearrangement of the glassy components and their segregation towards the substrate as well as the interaction of alumina with the conductor, by increasing the firing temperature. 
It is worthwhile stating a premise to the consideration of these experimental data. In fact accurate semiquantitative EDAX analyses are hindered in most of our samples by the poor density of the materials, in the sense discussed in the previous section. The density is much lower than the "theoretical" density, particularly for samples with $T_{f}<550^{\circ} \mathrm{C}$. As a result, the accuracy of the data is poor except for samples fired at very high temperatures and with carefully chosen experimental conditions. These effects are illustrated by the data shown in Figure 13 which gives the relative concentration $\mathrm{Pd} / \mathrm{Pd}+\mathrm{Ag}$ obtained in EDAX analyses with primary electron beams of 12 and $25 \mathrm{keV}$ respectively. The data evidence a constant ratio, near the actual value, in samples fired at $\mathrm{T}_{\mathrm{f}} \geqslant 600^{\circ} \mathrm{C}$, while the value diverges at unreal figures in samples fired at lower $T_{f}$. The higher the electron energy, the higher is the error in the quantitative evaluation, because of a greater effect of the poor density of the samples, which in turn produces unreal correction factors for the computer program.

Because of this "limitation" of the EDAX technique applied to our samples, the results of the following experiments are to be considered as indicative of a trend rather than as quantitative data.

Figure 14 shows the concentration of some elements in the layer, detected in samples fired at different $\mathrm{T}_{\mathrm{f}}$. The amount of $\mathrm{Zn}, \mathrm{Bi}, \mathrm{Si}$, and $\mathrm{Pb}$ decreases by increasing the firing temperature; this result is interpreted as a progressive segregation of these elements towards the film/substrate interface. As a result these elements leave the top surface of the film where the exciting electron-beam penetrates by only a few micrometers. ${ }^{9}$ This segration starts at $650^{\circ} \mathrm{C}-700^{\circ} \mathrm{C}$ i.e. at about the same temperature where DTA curves give the endothermic peak. This seems a non-fortuitious coincidence, suggesting a softening of the glass frit and its flow through the alloy grains for filling the open cavities. This process makes easier the sintering process ${ }^{2-3}$ and gives rise to shrinkage of the film (Figures 7, 11).

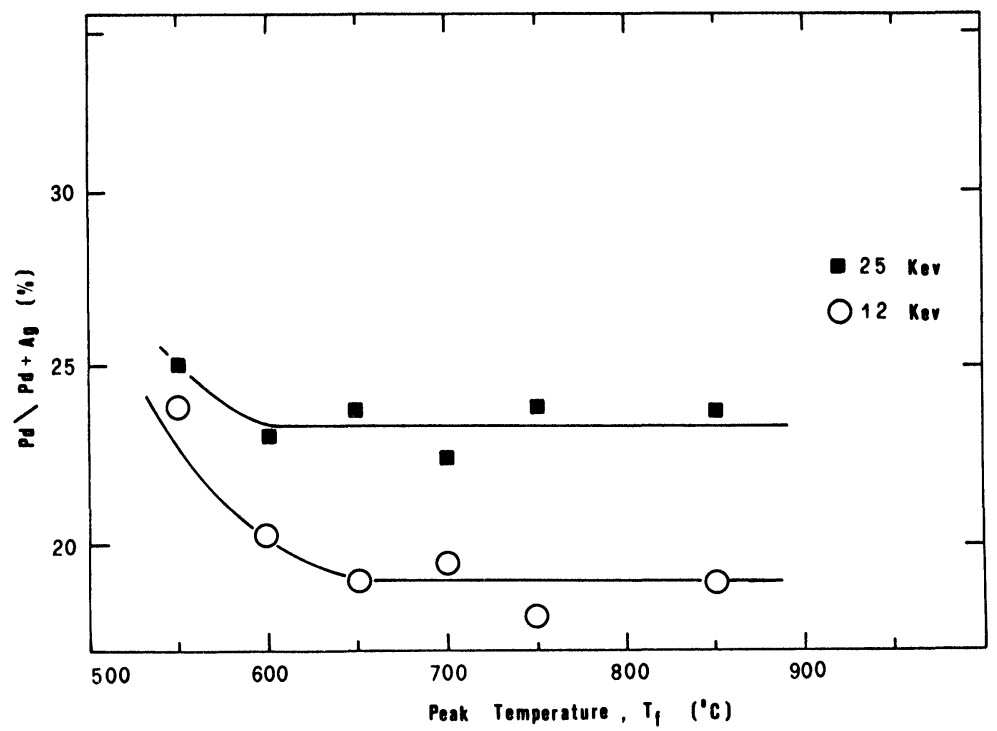

FIGURE $13 \mathrm{Pd} / \mathrm{Pd}+\mathrm{Ag}$ ratio in samples fired at different $\mathrm{T}_{\mathrm{f}}$, as determined by EDAX analysis. 


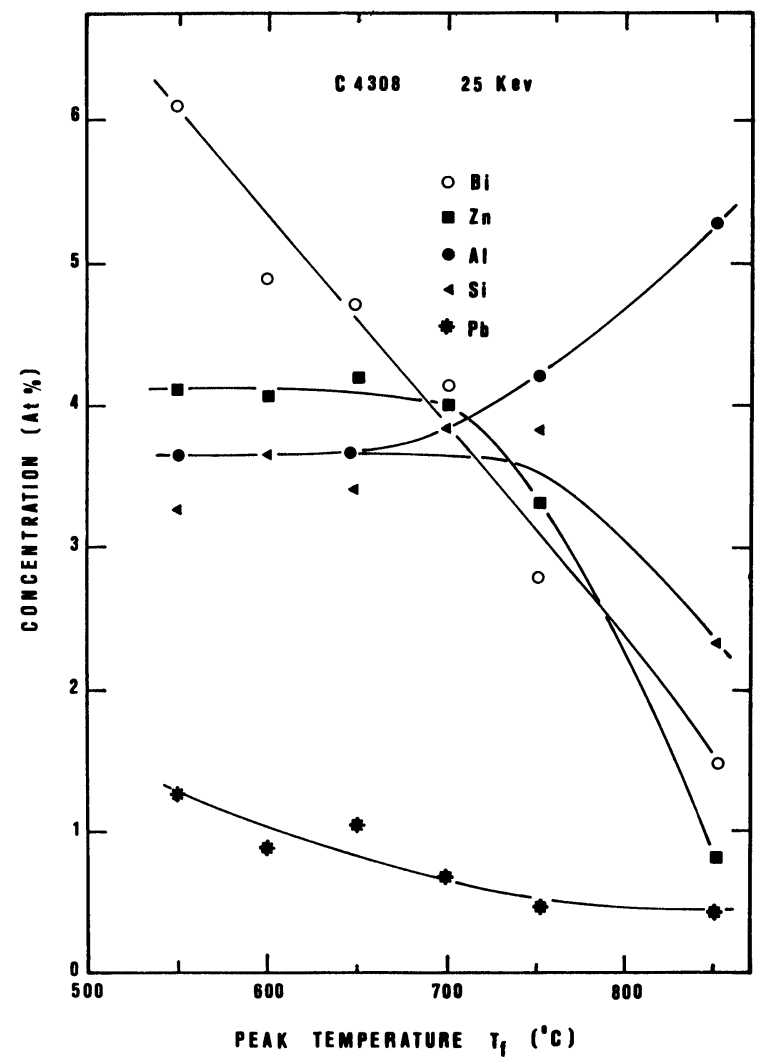

FIGURE 14 Atomic concentration of some elements as detected by the EDAX apparatus on the surface of samples fired at different $T_{f}$

The behavior of $\mathrm{Al}$ is different from that of $\mathrm{Bi}, \mathrm{Zn}, \mathrm{Si}$ and $\mathrm{Pb}$. In fact the amount of $\mathrm{Al}$ increases on the top of the conductive layer on increasing the firing temperature (Figure 14). In principle this experimental evidence should be due to either a segregation of the original amount of Al on the top of the film, or to an increase of the Al content because of an interaction with the alumina substrate. This latter alternative turns out to be the actual one according to EDAX analysis of samples fired at $850^{\circ} \mathrm{C}$, lapped at different thickness (Figure 15). An increasing amount of $\mathrm{Al}$ is detected by increasing the film depth toward the substrate. A very large diffusivity and solubility of $\mathrm{Al}$ in the glassy layer is suggested by the data. In passing, we may note that the data on Figure 15 supports the segregation of $\mathrm{Bi}$ on the substrate/film interface.

\section{Performance of the PdAg conductor}

Figure 16 shows the change of electrical properties of samples fired at different temperatures. $\mathbf{R}_{\mathrm{s}}$ represents the sheet resistance, namely the measured resistance value divided by the film aspect ratio, without any consideration of the change of the sample thickness, which is noticeable for $\mathrm{T}_{\mathrm{f}}>700^{\circ} \mathrm{C}$ (Figure 7). On the contrary $\rho$ represents the bulk resistivity of the samples, where the actual thickness is taken into account. 


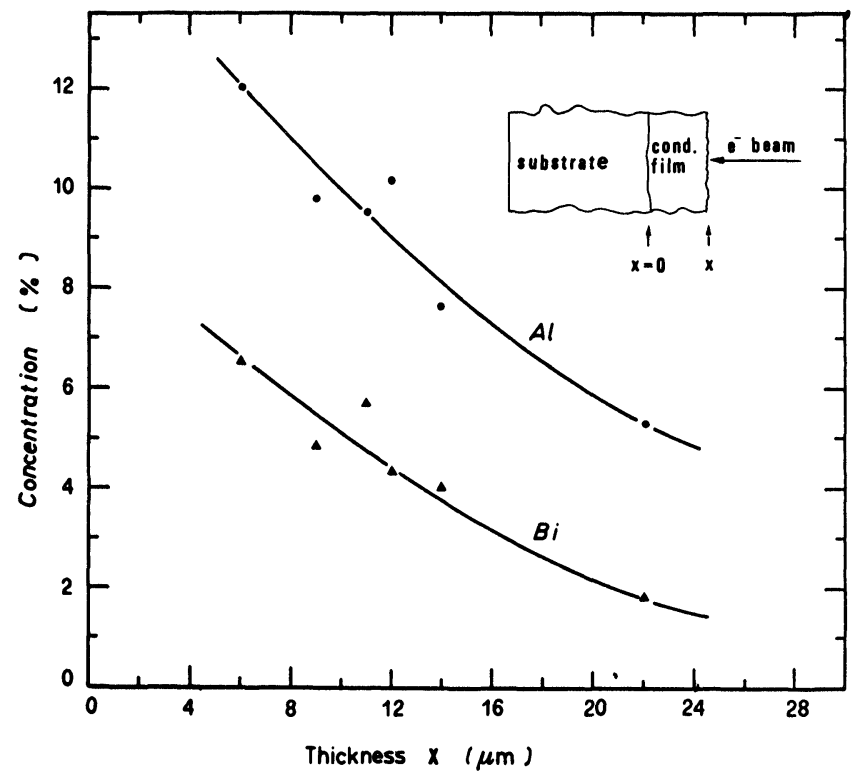

FIGURE 15 Atomic concentration of $\mathrm{Al}$ and $\mathrm{Bi}$ in samples $25 \mu \mathrm{m}$-thick, fired at $850^{\circ} \mathrm{C}$ and thinned by mechanical lapping at different thickness.

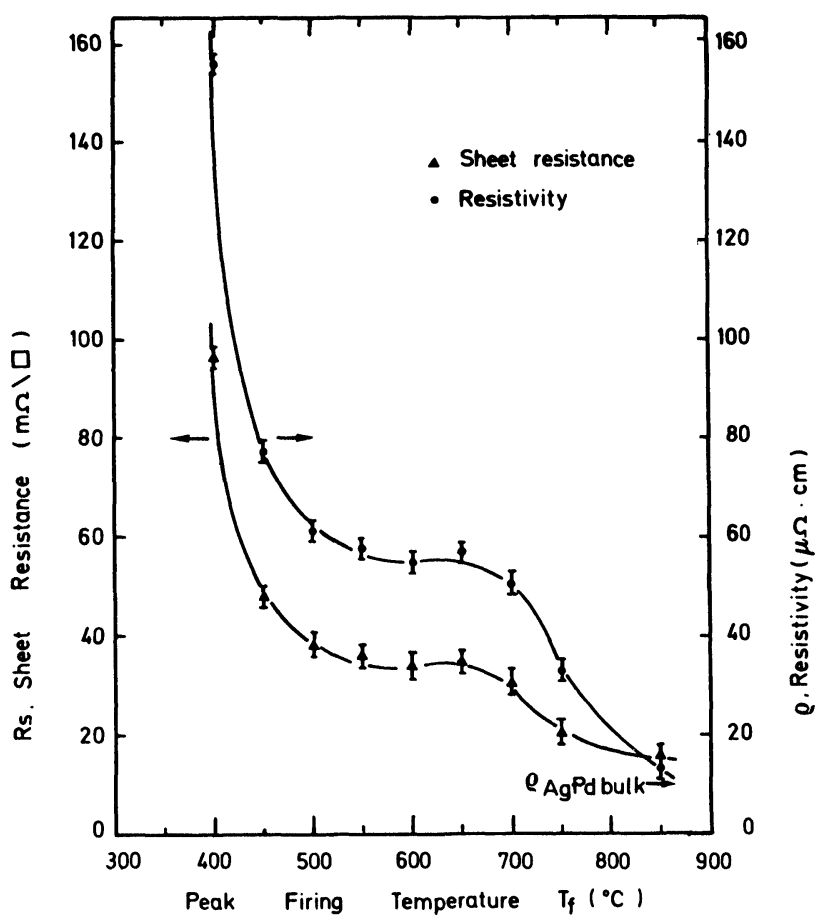

FIGURE 16 Sheet resistance $R_{s}$ and resistivity $\rho$ as a function of the peak firing temperature; $R_{s}$ is calculated neglecting the change of film thickness. $\rho$ values taken into account the actual thickness of the film. Note that the effective resistivity of the films fired at $850^{\circ} \mathrm{C}$ is about 1.4 times that of a bulk $\mathrm{AgPd}$ alloy of equal composition. 
The experimental data can be interpreted with the following considerations. Samples fired at $T_{\mathrm{f}} \leqslant 350^{\circ} \mathrm{C}$ exhibit extremely high resistances (in the $\mathrm{M} \Omega / \square$ range, not shown in Figure 16) due to the presence of the organic vehicle, which takes apart the metal particles and acts as an insulator between them. However at $T_{f} \geqslant 400^{\circ} \mathrm{C}$ the organic vehicle is completely removed (Figure 2 ) and the resistance drops rapidly to less than $100 \mathrm{~m} \Omega / \square$. In samples fired at $T_{f}$ from $450^{\circ} \mathrm{C}$ to $700^{\circ} \mathrm{C}, \mathrm{R}_{\mathrm{s}}$ exhibits small changes as a consequence of competing effects such as $\mathrm{Pd}$ oxidation, $\mathrm{PdO}$ reduction, alloy formation and alloy grain enlargement. Only in samples fired at $\mathrm{T}_{\mathrm{f}}>700^{\circ} \mathrm{C}$ do the sintering and rearrangement of the components in the layer actually reflect on the electrical properties of the material. In fact the resistivity changes by more than a factor two in passing from $T_{f}=700^{\circ} \mathrm{C}$ to $T_{f}=850^{\circ} \mathrm{C}$. Of course the resistance decrease is ascribed to various concurrent effects: the shrinkage of the film, and consequently minor distances and greater contact areas between the metal grains, the enlargement of the grains (that leads to lower electron scattering effects), and the segregation of part of the glass towards the substrate with the result that very thin dielectric films cover the metal grains.

It is interesting to note that the final resistivity $\left(\mathrm{T}_{\mathrm{f}}=850^{\circ} \mathrm{C}\right)$ is only 1.4 times larger than that of a bulk PdAg alloy of equal composition. ${ }^{12}$ This result is theoretically predicted ${ }^{13}$ when cubic metal particles are compacted at an actual density 0.95 times the theoretical density. This observation suggests that any glassy layer covering the metal particles is so thin that electrons can tunnel through it very easily.

As regards adhesion, we find that in samples fired at $\mathrm{T}_{\mathrm{f}} \leqslant 600^{\circ} \mathrm{C}$ the peel strength was too low for an accurate measurement. The adhesion in samples fired at $\mathrm{T}_{\mathrm{f}}=650^{\circ} \mathrm{C}$ failed at the film/substrate interface with a peel strength of about $8 \mathrm{~N} / \mathrm{mm}^{2}$, whereas for $\mathrm{T}_{\mathrm{f}} \geqslant 700^{\circ} \mathrm{C}$ the adhesion is excellent, since the failure occurs with breaking of the alumina substrate and a peel strength in the range from 15 to $20 \mathrm{~N} / \mathrm{mm}^{2}$.

These results show that the evolution of the microstructure of the film plays a relevant role in the mechanical properties and adhesion of the conductor. In fact the segregation of the glassy components at the substrate interface, as well as the interaction of alumina with the film, occurs at just those temperatures where the adhesion behavior improves substantially. The change of adhesion around $650-700^{\circ} \mathrm{C}$ is clearly a consequence of these chemico-physical modifications of the conductive layer near the substrate interface.

\section{DISCUSSION AND CONCLUSION}

In the present paper we have shown that the evolution of the microstructure of an actual thick-film conductor is rather more complex than a simple sintering of metal grains. A general picture of the effects occurring in the firing cycle can be obtained from the study. of samples fired at intermediate peak temperatures with isochronal cycles.

The picture emerging from the study of the conductor described in this paper is shown in Figure 17. The description of the evolution of the microstructure can be simplified by defining schematically three different temperature ranges.

In the first one, a "low temperature range" up to about $350^{\circ} \mathrm{C}$, the film is made of submicron particles of $\mathrm{Ag}, \mathrm{Pd}, \mathrm{Bi}_{2} \mathrm{O}_{3}$, a glass frit and organic vehicle. In the range of "intermediate temperatures", from about $400^{\circ} \mathrm{C}$ to $650^{\circ} \mathrm{C}$ the system is made of $\mathrm{Pd}-\mathrm{Ag}$ alloy grains sintered at a low density, as well as glassy and microcrystalline particles of non-metal components. In the range of "high temperatures" from $700^{\circ} \mathrm{C}$ to $850^{\circ} \mathrm{C}$ the microstructure becomes very compact but differentiated in the film thickness; in fact near the substrate we find the glassy components, reacted with the alumina, while in the upper layers of the films we find essentially a $\mathrm{PdAg}$ alloy sintered at closed porosity, approaching the theoretical density. 


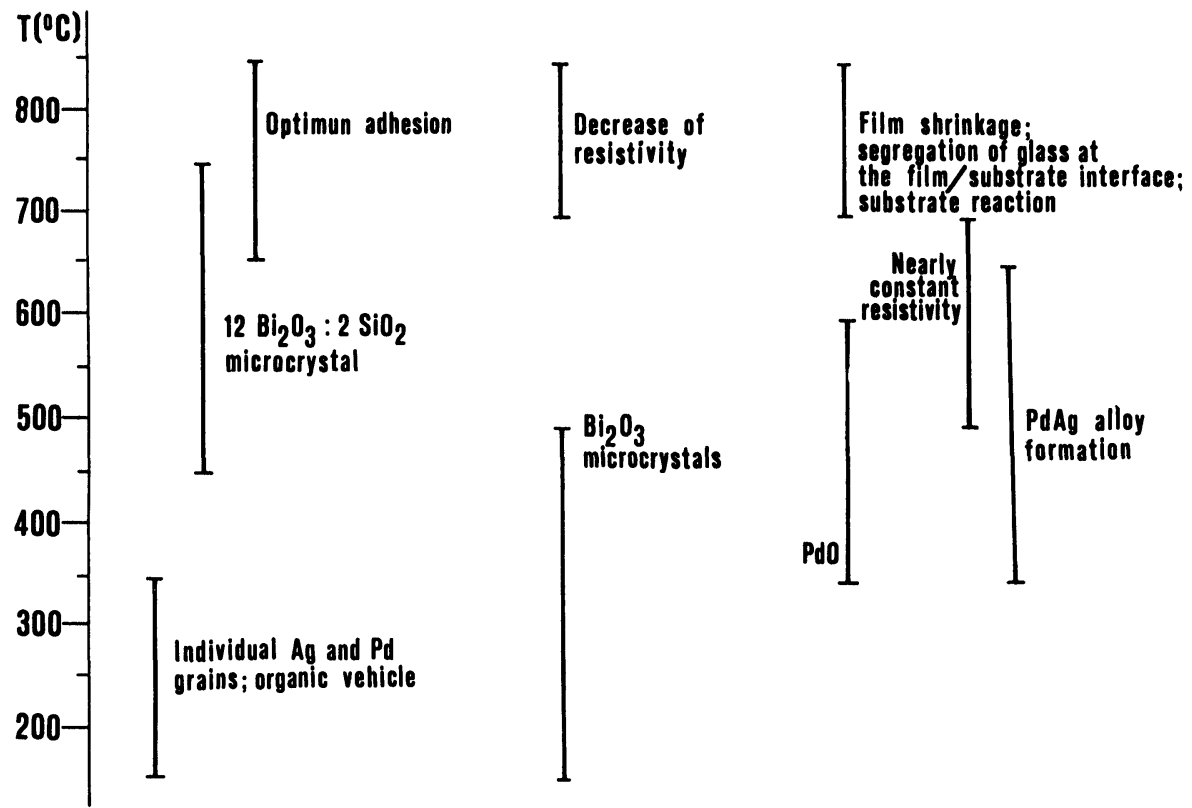

FIGURE 17 A sketch of the phenomena occurring during the firing cycle of the conductor and some correlation of these phenomena with the performance of the film.

The boundary between the ranges of low and intermediate temperatures seems closely correlated with the physico-chemical properties of the organic vehicle; namely, this latter must burn out in order to allow a reaction between $\mathrm{Ag}$ and $\mathrm{Pd}$ (at atomic level), an oxidation of $\mathrm{Pd}$ and a reduction of $\mathrm{Bi}_{2} \mathrm{O}_{3}$. Moreover the burn out of the organic vehicle promotes a contact of the metal particles, changing the electrical behavior of the film, from an insulator to a conductor.

The boundary between the ranges of intermediate and high temperatures seems closely correlated with the properties of the glass frit (including the bismuth compound). In fact the glass must assume a low viscosity and wet the metal particles; as a result we have easier sintering of the grains, the shrinkage of the film as well as a chemical interaction with the substrate which promotes the adhesion. Probably the reduction of $\mathrm{Bi}_{2} \mathrm{O}_{3}$ and the interaction of $\mathrm{Bi}$ with the glass frit is very relevant in the determination of the wetting properties and viscosity of the glass. ${ }^{15}$

It is interesting that the conductor can be "ready to use" even when fired at $T_{\mathrm{f}}$ as low as $500^{\circ}-550^{\circ} \mathrm{C}$, since its sheet resistance is already that of a good conductor and improves only by a factor two on increasing $\mathrm{T}_{\mathrm{f}}$ to $850^{\circ} \mathrm{C}$. It is only the need for good adhesion that requires $\mathrm{T}_{\mathrm{f}} \geqslant 700^{\circ} \mathrm{C}$.

Besides the interesting results discussed hitherto on the specific material, the present work also enabled us to check a general method of investigations for the study of thickfilm conductors. It is worthwhile to review briefly some points emphasized by this work.

Let us start from the obvious point that an exhaustive picture of the formation of the microstructure of thick-film conductors emerges only from the results of several complementary analytical techniques.

TG analysis, with its simplicity and unambiguous results, is essential for understanding the behavior of the organic vehicle during the firing process. We found difficulty in interpreting of DTA data in the complex system studied, but the technique can be useful for studying the softening point of the glass. X-ray diffractometry is 
extremely informative on the phase changes and interaction between the film components, grain sizes (as long as they are lower than about $2000 \AA$ ); moreover, some quantitative data on the film composition can be obtained from the areas of diffraction peaks as well as from the peak shift of isomorphous phases which form an alloy. The penetration depth of $\mathrm{Cu}-\mathrm{K} \alpha$ beams of the usual X-ray sources is high enough for the investigation of layers several micrometers thick, so that no particular expedient for the preparation of the samples is necessary for X-ray diffraction analysis.

Also SEM and EDAX techniques are very useful for a study of thick-film materials, provided that care is taken in choosing the measuring conditions and interpreting of the data. In fact we obtained clear evidence of the artefacts in quantitative analyses due to the porosities and poor density of samples.

In conclusion, this work has provided interesting results on the evolution of the microstructure of $\mathrm{Pd} / \mathrm{Ag}$ based conductors and its correlation with the performance of the films. Moreover the study has provided a test of experimental methods for the investigation of thick-film conductors for microelectronics and photovoltaic applications.

\section{ACKNOWLEDGEMENT}

This work was partially supported by Consiglio Nazionale delle Ricerche and Ministero della Pubblica Istrwzione, Italy. It is a pleasure to thank the staff of Centro Strumenti dell Universitá di Modena for assistance in use of SEM, EDAX and TESAK.

\section{REFERENCES}

1. R.D. Jones, Hybrid Circuits I.)esign and Manufacture (M. Dekker, New York, 1982).

2. S.S. Cole Jr., "Sintering of Ag-Pd in the presence of a reactive glass", J. Am. Ceram. Soc. 55 (1972), 296.

3. S.S. Cole Jr., "The sintering mechanism of a silver palladium film" Int. Hybrid Microel. Conf. (1972) 2-A-1.1.

4. L.F. Miller, "Silver Palladium fired electrodes" Proc. IEEE ECC (1968) 52.

5. G.P. Wirtz, "Adhesive strength of thick-film Pd-Ag conductors" Proc. Electr. Comp. Conf. (1971) 480.

6. T.T. Hitch and K.K. Bube, "Basic adhesion mechanism in thick and thin films", Report from RCA Labs., Princeton N.J. 31 Jan. 1975.

7. H.C. Kim, W. Rothlungshofer, and G. Tomandl, "Adhesion mechanism of thick-film conductors", Sol State Technol (1969) March, 62.

8. D.C. Wood, "Performance of thick-film materials on $96 \%$ alumina substrates", Insulation/circuits, May-July 1980.

9. S.J.B. Reed, "Electron microprobe analysis", Cambridge University Press (1975).

10. A. Taylor, "X-ray metallography", Wiley, New York (1961).

11. W.D. Kingery, "Introduction to ceramics", John Wiley and Sons, (1976).

12. International Critical Tables, 6, pg. 160, McGraw Hills Co. New York (1930).

13. T. Ramanan and A.C.D. Chaklader, "Electrical resistivity of hot-pressed compacts", J. Am. Ceram. Soc. $58,(1975) 476$

14. C. Nagabhushana Rao and K. Krishna Rao, "Effect of temperature on the lattice parameters of some silver-palladium alloys", Canad. J. Phys. 42, (1964) 1336.

15. M. Monneraye, "Les encres serigraphiables en microelectronique hybride: les materiaux et leur comportement", Acta Electronica 21 (1978) 263. 

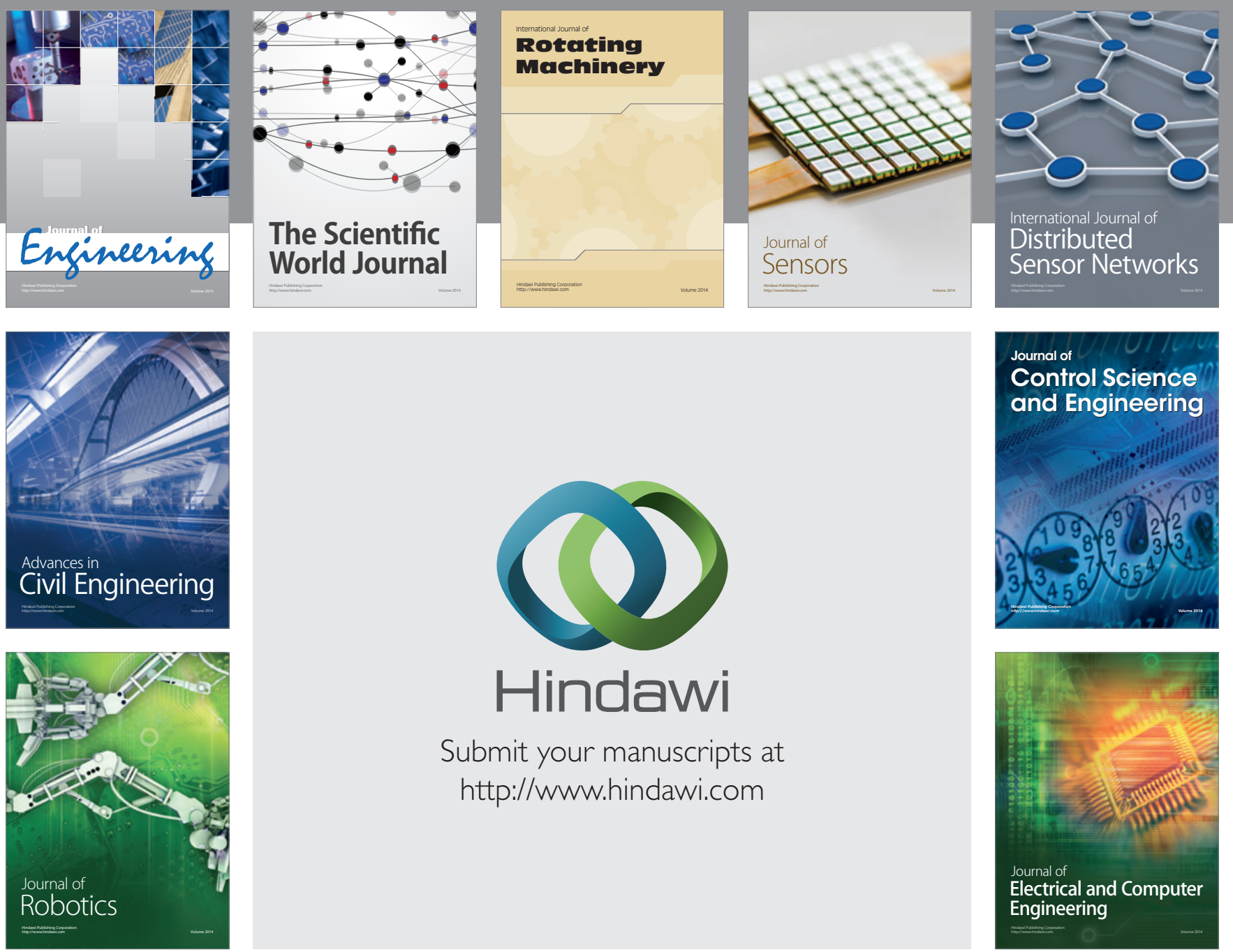

Submit your manuscripts at

http://www.hindawi.com
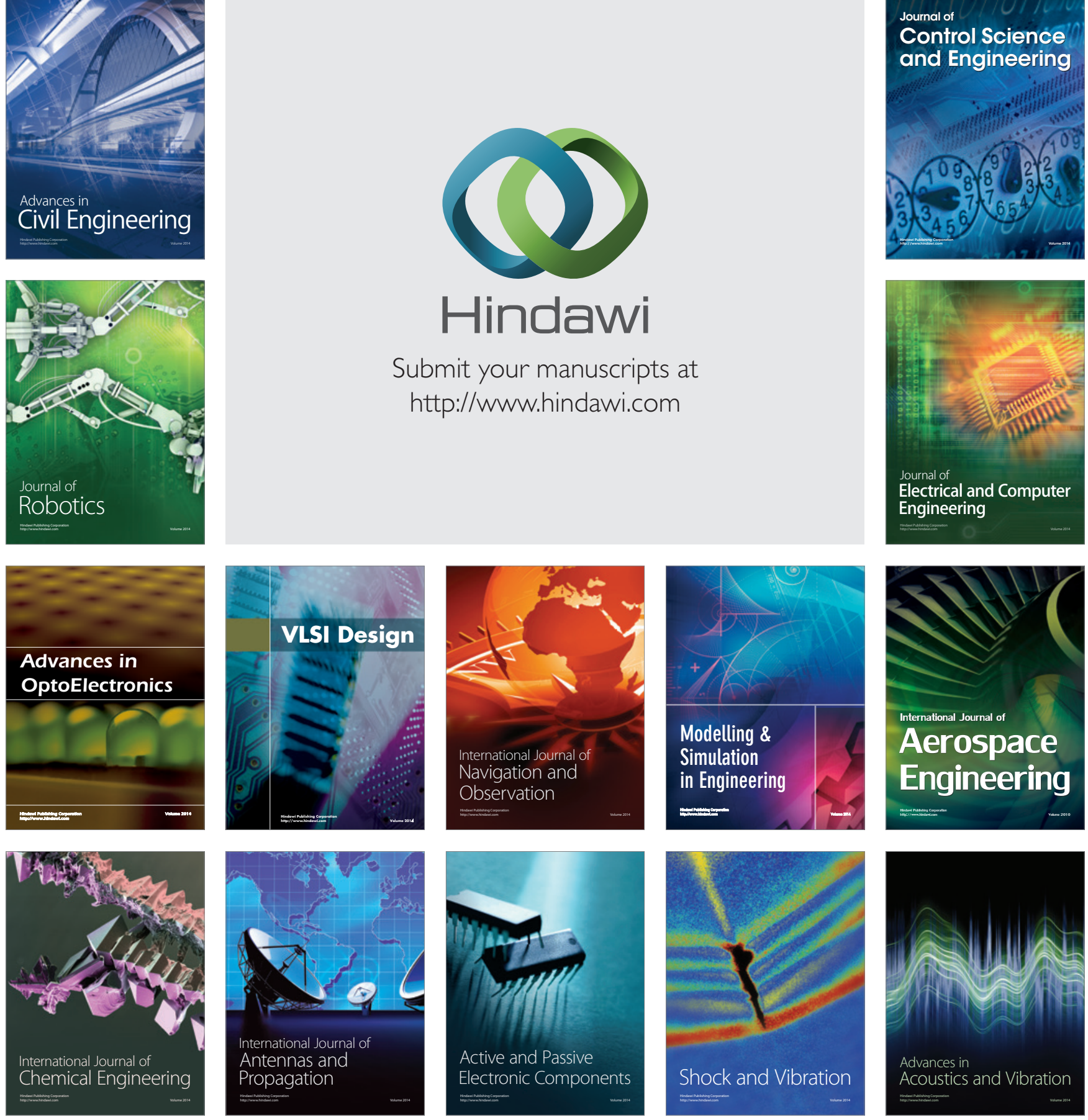